\title{
Ceramic microspheres to improve anticorrosive performance of phosphate paints
}

\author{
C. Deyá*, B. del Amo, R. Romagnoli \\ CIDEPINT (Centro de Investigación y Desarrollo en Tecnología de Pinturas), Calle 52 entre 121 y 122, (B1900AYB) La Plata, Argentina
}

Received 8 June 2011; received in revised form 14 October 2011; accepted 10 November 2011

Available online 20 November 2011

\begin{abstract}
Zinc phosphate and related compounds have been proposed as "green" replacements for traditional anticorrosive pigments such as zinc chromate and lead oxides. However, environmental concerns have risen in the last years because the disposal of these materials in the environment increased phosphate levels in water and produce eutrophication of water bodies. The present paper deals with the possible incorporation of ceramic microspheres in alkyd paints in order to diminish phosphate content. The results suggested that paints with low phosphate content can be successfully formulated with a suitable selection of the amount and type of microspheres.
\end{abstract}

(C) 2011 Elsevier Ltd and Techna Group S.r.l. All rights reserved.

Keywords: Zinc phosphate; Ceramic microspheres; Anticorrosive paints; Barrier properties

\section{Introduction}

Zinc phosphate and related compounds have gained worldwide acceptance as suitable replacements for traditional anticorrosive pigments such as zinc chromate and lead oxides [1-4]. However, environmental concerns about phosphatepigmented primers have risen because the disposal of these materials in the environment increased phosphate levels in water and produce eutrophication of water environments $[5,6]$. Eutrophication is a process caused by an excess of nutrients which stimulate excessive plant growth. Plants lower oxygen concentration, diminish light penetration and, as result, the biological community changes (Fig. 1). As a consequence, scientific research is focused on eliminating or, at least, diminishing phosphate content in paints.

There are two stages in the story of anticorrosive pigments for protective paints. The first one was the substitution of zinc chromates and lead oxides by zinc phosphates [1-3] and modified phosphates [7-10]. Apart from phosphates, ion exchanged silicas [11-14], spinels [15,16] and borates [17], were reported to have good anticorrosive properties. Lamellar pigments such as mica, micaceous iron oxide and aluminium

\footnotetext{
* Corresponding author. Tel.: +54 0221 4831144; fax: +54 02214271537 E-mail address: pinturashigienicas@cidepint.gov.ar (C. Deyá).
}

leaves were also studied because they diminish film permeability to water and aggressive ions, thus restraining corrosion of the metal substrate [18-20].

The second stage was dominated by the search of "green pigments" designed to exhibit either intelligent behaviour or synergisms with other pigments. In this field the employment of conducting polymers (polyaniline and polypirrol) [21-25] and mixtures of pigments such as phosphate and hypophosphite [26], polyaniline with phosphates or borates [27], etc. could be found in the literature.

The present work studied the incorporation of two different silica-alumina-ceramic-spheres to paints in order to lower the zinc phosphate content without impairing their anticorrosive properties. These aluminosilicates were characterized by current analytical techniques and their protective properties by electrochemical tests (corrosion potential and linear polarization measurements). Solvent borne paints were formulated employing an alkyd resin as film forming material. Steel panels were painted and, then, tested in the salt spray cabinet and the humidity chamber. Paints anticorrosive performance was also assessed by electrochemical tests such as corrosion potential and ionic resistance measurements. Results showed that the main action of the microspheres was to enhance the barrier properties of the coating in such a way that zinc phosphate content can be diminished sensibly. 


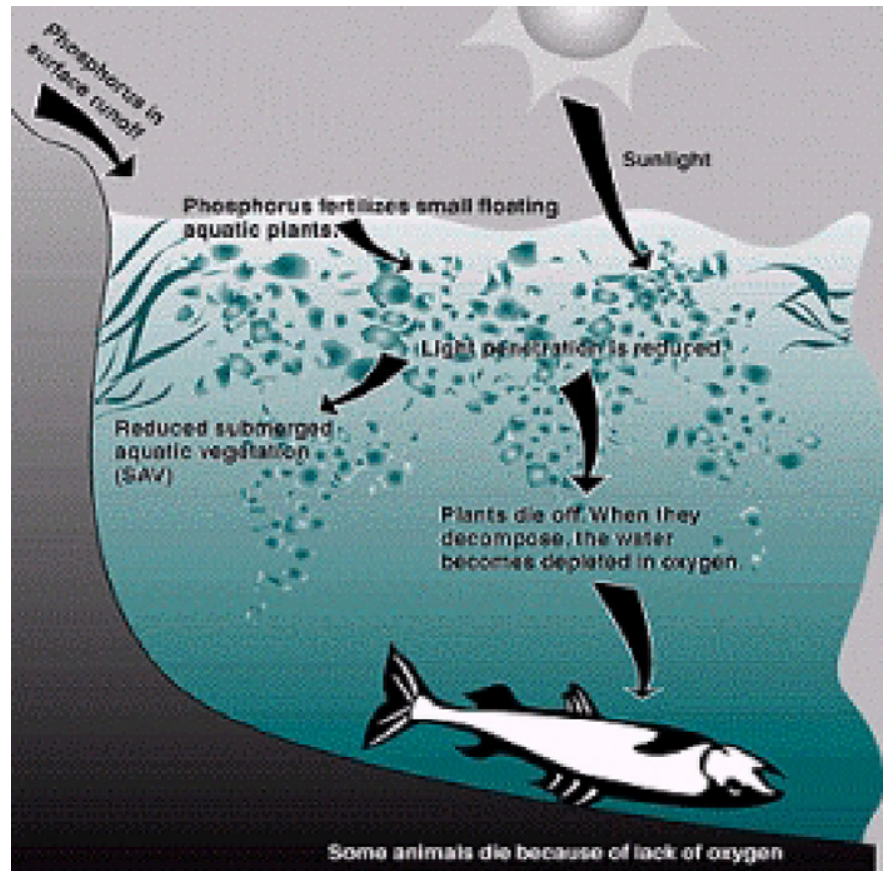

Fig. 1. Biological effects of eutrophicacion. From "Phosphate removal: a novel approach", J.W. Mc Grath and J.P. Quinn.

\section{Materials and methods}

\subsection{Pigments characterization}

Two different ceramic microspheres ( $\mathrm{G}$ and $\mathrm{W}$ ) were selected to carry out this research. Their characteristics may be found in the corresponding technical sheet $[28,29]$

The composition of the aluminosilicate microspheres was obtained by current analytical techniques. Their physicochemical properties relevant to paint technology, such as density and oil absorption, were determined according to standarized procedures (ASTM D 1475 and ASTM D 281, respectively). The size of the spheres was determined with a Malvern Particle Analyzer and their shape was observed by Scanning Electron Microscopy (SEM). pH, conductivity and soluble salts content of their water extracts were also determined.

Electrochemical essays were done in order to ensure that ceramic spheres do not influence steel corrosion. Corrosion potential of SAE 1010 steel electrodes immersed in a suspension of the spheres in $0.025 \mathrm{M} \mathrm{NaCl}$ was measured as a function of time, employing a saturated calomel electrode (SCE) as reference.

Steel corrosion rate in $\mathrm{G}$ and $\mathrm{W}$ pigments suspensions, in $0.1 \mathrm{M} \mathrm{NaCl}$, was obtained from polarization curves employing Tafel's approximation. A SCE and a platinum grid were used as reference and counterelectrode, respectively. The swept amplitude was $\pm 0.250 \mathrm{~V}$ from the open circuit potential and the scan rate $0.5 \mathrm{mV} \mathrm{s}^{-1}$. Measurements were carried out with a Potentiostat/Galvanostat EG\&G PAR Model 273 A plus SOFTCORR 352 software.

\subsection{Formulation, elaboration and application of paints}

A medium oil alkyd resin (50\% linseed oil, $30 \%$ o-phtalic anhydride, $8 \%$ pentaerythritol and glycerol and $12 \%$ pentaerythritol resinate) was employed as the film-forming material and white spirit as the solvent. The pigment volume concentration/critical pigment volume concentration ( $\mathrm{PVC} /$ CPVC) relationship was 0.8 . It should be pointed out that a solvent borne alkyd resin was chosen because its behaviour has been well documented for many years.

Paints were formulated with different ceramic spheres/ barium sulphate ratios $(100 / 0,70 / 30,50 / 50$, by volume, v/v). The anticorrosive pigment was zinc phosphate $(10 \%$, v/v respect to the total pigment content) while titanium dioxide and zinc oxide were the complementary pigments.

Two control paints were formulated: one of them with $10 \%$ $(\mathrm{v} / \mathrm{v})$ of zinc phosphate, the other with $30 \%(\mathrm{v} / \mathrm{v})$. This last content was recommended in the specialized literature to achieve good anticorrosive performance while a poor behaviour was observed with $10 \%$ of zinc phosphate [4]. Pigment compositions are shown in Table 1.

All pigments were dispersed for $24 \mathrm{~h}$ in the vehicle (resin plus solvent), employing a ball mill, to achieve an acceptable dispersion degree.

SAE 1010 steel panels $(15.0 \mathrm{~cm} \times 7.5 \mathrm{~cm} \times 0.2 \mathrm{~cm})$ were sandblasted to Sa 2 1/2 (SIS 0559 00), degreased with toluene and, then, painted by brush, to reach a dry film thickness of $70 \pm 5 \mu \mathrm{m}$. Painted panels were kept indoors for 14 days before testing.

From now on, paints will be named with the letter corresponding to the type of sphere employed in the formulation $(\mathrm{G}$ or $\mathrm{W})$ and with a number, corresponding to the pigment formulation (1, 2 or 3$)$ displayed in Table 1. Paints

Table 1

Pigment composition of paints as percentage by volume of solids.

\begin{tabular}{|c|c|c|c|c|c|}
\hline \multirow{2}{*}{ Components } & \multicolumn{5}{|l|}{ Paints } \\
\hline & 1 & 2 & 3 & 4 & 5 \\
\hline $\mathrm{G}$ or $\mathrm{W}$ & 35.4 & 25.3 & 17.7 & - & - \\
\hline Zinc phosphate & 10.0 & 10.0 & 10.0 & 10.0 & 30.0 \\
\hline Titanium dioxide & 19.2 & 19.2 & 19.2 & 19.2 & 11.9 \\
\hline Zinc oxide & 35.4 & 35.4 & 35.4 & 35.4 & 29.1 \\
\hline Barium sulphate & 0.0 & 10.1 & 17.7 & 35.4 & 29.1 \\
\hline $\mathrm{G}$ or $\mathrm{W} /$ Barium sulphate ratio & $100 / 0$ & $70 / 30$ & $50 / 50$ & $0 / 100$ & $0 / 100$ \\
\hline
\end{tabular}


Table 2

Physical and chemical properties of the spheres.

\begin{tabular}{|c|c|c|c|c|c|c|c|}
\hline \multirow[t]{2}{*}{ Microspheres } & \multicolumn{4}{|l|}{ Solid } & \multicolumn{3}{|l|}{ Aqueous extract } \\
\hline & \multicolumn{2}{|c|}{$\begin{array}{l}\text { Main composition } \\
(\% \mathrm{w} / \mathrm{w})\end{array}$} & $\begin{array}{l}\text { Density } \\
(\mathrm{g} / \mathrm{ml})\end{array}$ & $\begin{array}{l}\text { Oil absorption } \\
(\mathrm{ml} / \mathrm{g})\end{array}$ & $\begin{array}{l}\text { Soluble material } \\
(\mathrm{mg} / \mathrm{g} \text { of sphere) }\end{array}$ & $\begin{array}{l}\text { Conductivity }^{\mathrm{a}} \\
(\mu \mathrm{S} / \mathrm{cm})\end{array}$ & $\mathrm{pH}$ \\
\hline G & 53.6 & 38.6 & 2.20 & 0.293 & 1.6 & 128 & 6.68 \\
\hline $\mathrm{W}$ & 58.5 & 26.0 & 1.80 & 0.175 & 1.7 & 97.9 & 9.25 \\
\hline
\end{tabular}

${ }^{a}$ Conductivity of $0.1 \mathrm{~N} \mathrm{KCl}: 11,970 \mu \mathrm{S} / \mathrm{cm}$

$4(10 \%, \mathrm{v} / \mathrm{v})$ and $5(30 \%, \mathrm{v} / \mathrm{v})$ are the control paints with zinc phosphate.

\subsection{Observation of the coating film by SEM}

The characteristics of the dried paints surface and their cross section were observed by SEM employing a PHILLIPS SEM 505 .

\subsection{Performance of anticorrosive paints in accelerated and electrochemical tests}

A set of three panels per paint was placed in the salt spray chamber (ASTM B-117). Rusting (ASTM D-610) and blistering (ASTM D-714) degrees were evaluated after 720, 1100 and $1900 \mathrm{~h}$ of exposure. Failure at the scribe (ASTM D 1654) was also evaluated after 720 and $1100 \mathrm{~h}$.

Another set of painted panels was placed in the humidity chamber at $38 \pm 1{ }^{\circ} \mathrm{C}$ (ASTM D 2247) and, again, rusting and blistering degrees were assessed over time, after 200, 390 and $1100 \mathrm{~h}$.

The ionic resistance between the coated steel substrate and a platinum electrode was measured in the cell obtained by fixing an acrylic tube, $2 \mathrm{~cm}$ diameter, on the painted specimen and filling it with $0.5 \mathrm{M}$ sodium chloride. Measurements were carried out employing an ATI Orion, model 170, conductivity meter at $1000 \mathrm{~Hz}$.

The corrosion potential (Ecorr) of the painted steel was measured in the same cell using a saturated calomel electrode as the reference electrode and a high impedance voltmeter.

\section{Results and discussion}

\subsection{Pigments characterization}

Both ceramic microspheres contained a similar amount of $\mathrm{SiO}_{2}$ but those named as pigment $\mathrm{G}$ had higher content of $\mathrm{Al}_{2} \mathrm{O}_{3}$, which could be associated with the lower $\mathrm{pH}$ value of the pigment suspension due to the cation hydrolysis (Table 2).

The microspheres properties, relevant to paint technology, are also shown in Table 2 as well as the soluble material and the conductivity of each aqueous microsphere suspension. These last values were similar in both pigment suspensions and approximately one hundred times lower than specific conductivity of $\mathrm{KCl} 0.1 \mathrm{M}$
The average particle size for microspheres $\mathrm{G}$ and $\mathrm{W}$ was $12 \mu \mathrm{m}$ and $24 \mu \mathrm{m}$, respectively. It is though that spheres with pigments of different sizes could contribute to a better particle packing in the film. The smallest particles occupied the voids between the largest ones, thus hindering ionic diffusion through the paint film with the concomitant increase of the barrier effect of the paint. The electrochemical parameter selected to account for this feature was the ionic resistance.

Ecorr of steel in contact with the suspension of microspheres $G$ was more positive than that of the blank (steel in the supporting electrolyte). The Ecorr of steel was displaced to more positive values when microspheres $\mathrm{W}$ were employed maintaining a difference of $\sim 40 \mathrm{mV}$ at the end of the test period (Fig. 2). The measured corrosion potentials did not seem to indicate the passivation of the steel substrate (Table 3).

Polarization tests showed that none of the microspheres protected steel against corrosion. Actually, steel corrosion rate was higher in the presence of the microspheres, particularly with microsphere $\mathrm{W}$, than in the supporting electrolyte (Fig. 3 and Table 3). Corrosion potential obtained from polarization curves were different from the values reported in Fig. 2 due to the differences in $\mathrm{NaCl}$ concentration. The highest $\mathrm{NaCl}$ content in polarization tests was necessary to avoid the undesirable high ohmic drops in the cell.

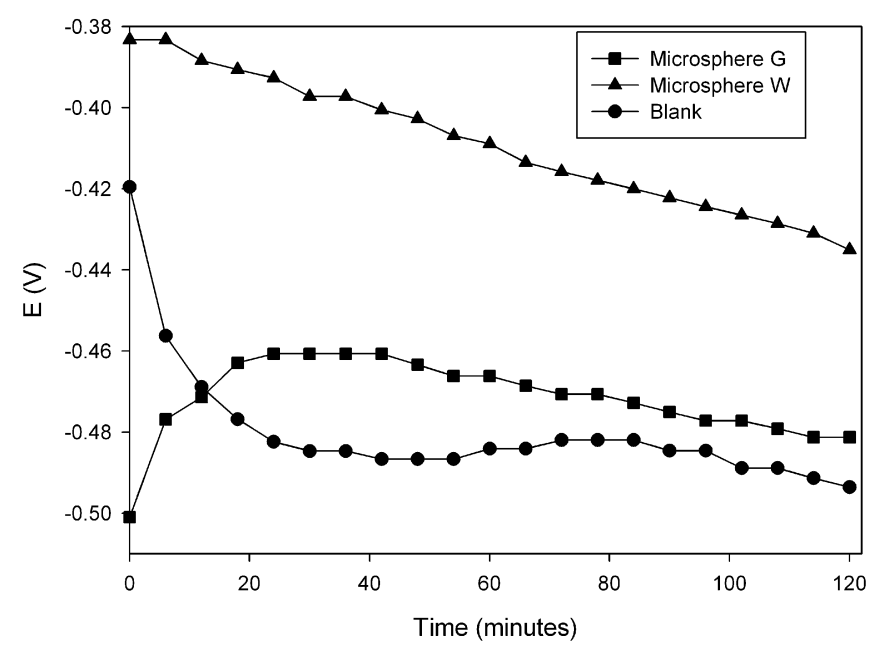

Fig. 2. Corrosion potential of the steel immersed in the microsphere suspensions. 
Table 3

Corrosion potential, polarization resistance and corrosion rate from Tafel curves of the steel immersed in microspheres suspensions.

\begin{tabular}{llllc}
\hline Microspheres & $2 \mathrm{~h}$ & $24 \mathrm{~h}$ & & \\
\cline { 2 - 5 } & $E(\mathrm{mV})$ & $E(\mathrm{mV})$ & $R_{p}\left(\mathrm{k} \Omega \mathrm{cm}^{2}\right)$ & $I_{\text {corr }}\left(\mu \mathrm{A} / \mathrm{cm}^{2}\right)$ \\
\hline $\mathrm{G}$ & -481 & -628 & 0.83 & 62.9 \\
$\mathrm{~W}$ & -459 & -599 & 0.30 & 137.4 \\
Blank & -493 & -604 & 0.45 & 47.7 \\
\hline
\end{tabular}

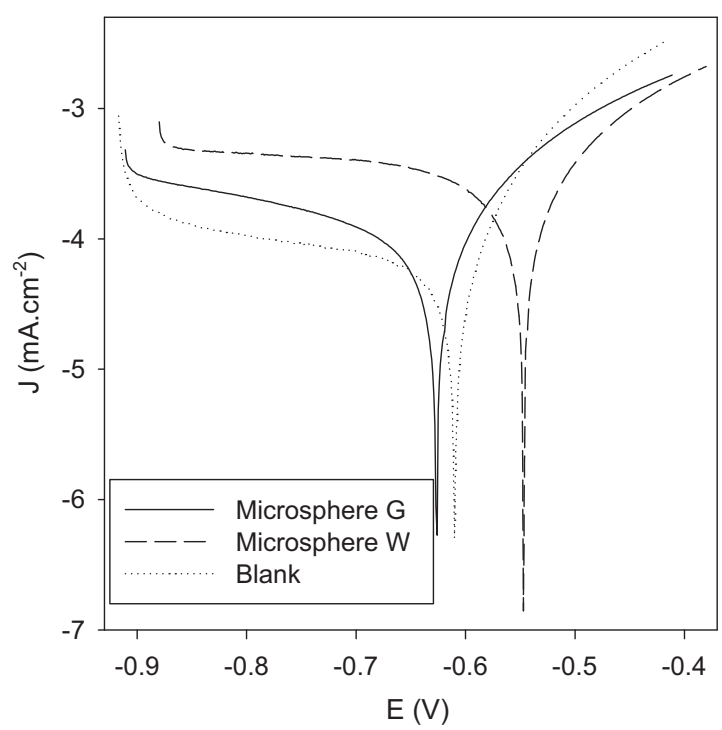

Fig. 3. Tafel curves of steel immersed in microsphere suspensions.

\subsection{Observation of the coatings film by Scanning Electron Microscopy (SEM)}

The shape of the ceramic particles $\mathrm{G}$ was mostly spherical but microspheres $\mathrm{W}$ have an important amount of non-spherical particles (Fig. 4).

Full replacement of barite by spheres type $\mathrm{G}$ in paint $\mathrm{G} 1$ generated a surface with few pores and a rather smooth and compact film (Fig. 5). As the percentage of barite increased, the surface became smoother (Figs. 5-7).

When barite was totally replaced by $\mathrm{W}$ spheres, paint $\mathrm{W} 1$, the surface was granular and the film was compact (Fig. 8).

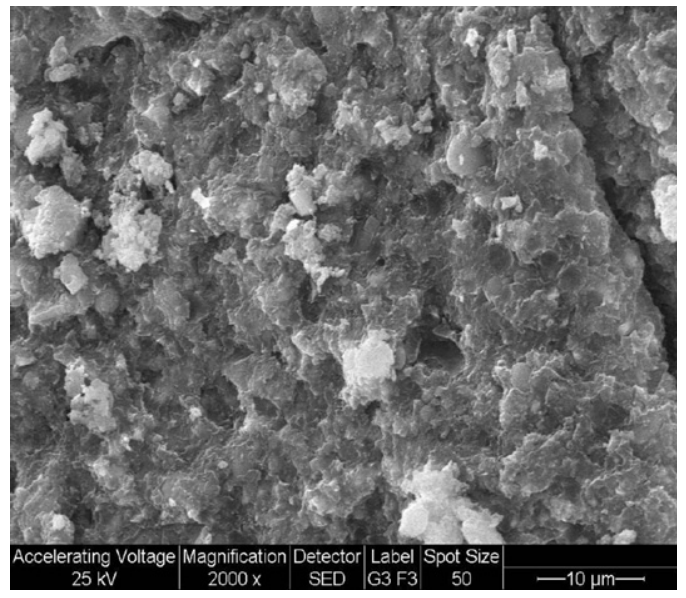

Fig. 5. SEM image of paint G1 cross section area.

When $70 \%$ of barite was replaced, the surface was still granular and the film appeared to be a little more porous (Fig. 9). Film porosity increased when $50 \%$ of the barite was replaced by $\mathrm{W}$ spheres and cracks developed along the surface and many pores may be seen (Fig. 10). It was thought that these cracks and pores impaired paints protective properties. Cracks may be attributed to internal tensions in the film.

The reference coating (paint 4) is a porous one (Fig. 11). When the percentage of zinc phosphate increased from $10 \%$ to $30 \%$, with the consequently decreased in all the inert pigments content, the porosity diminished notably (Fig. 12). As pores also appeared in paints without microspheres, it was thought that pores formed by the presence of barite because their number was higher when the percentage of barite was higher (Figs. 11 and 12).

\subsection{Performance of anticorrosive paints in accelerated and electrochemical tests}

In the salt spray cabinet, all paints formulated with ceramic spheres performed better than the control paint with $10 \%$ of zinc phosphate (paint 4). The exception was paint W3 (spheres/ barium sulphate ratio 50/50) (Table 4) whose panels were taken out the chamber after $1100 \mathrm{~h}$. Paints with microspheres G and
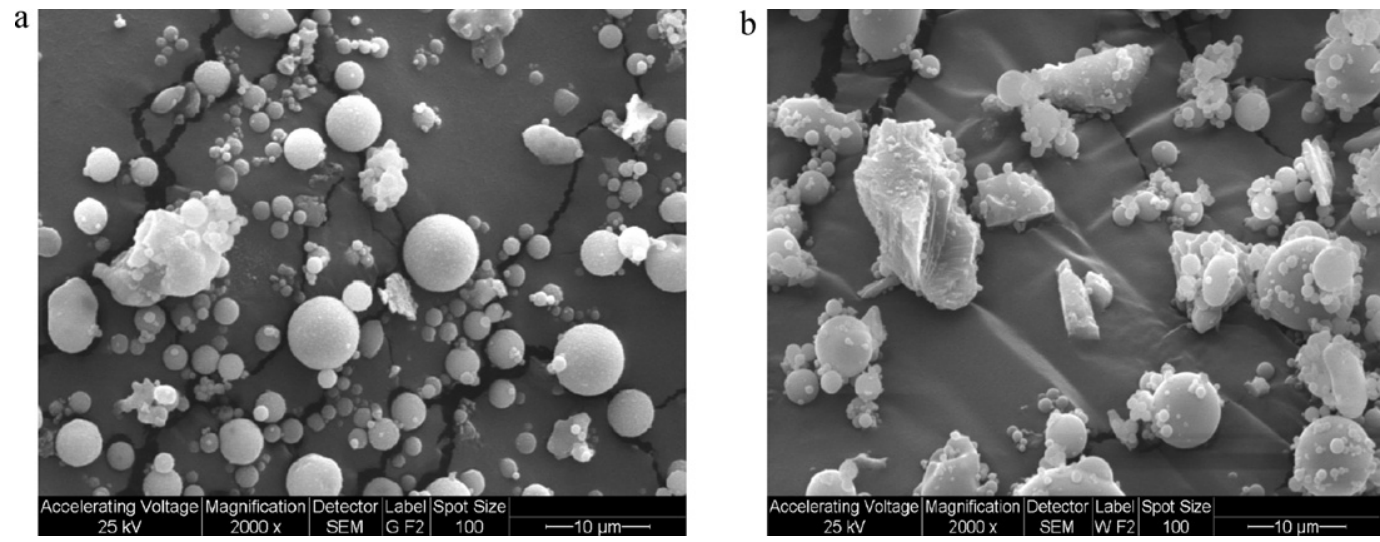

Fig. 4. SEM image of (a) spheres G, (b) spheres W. 


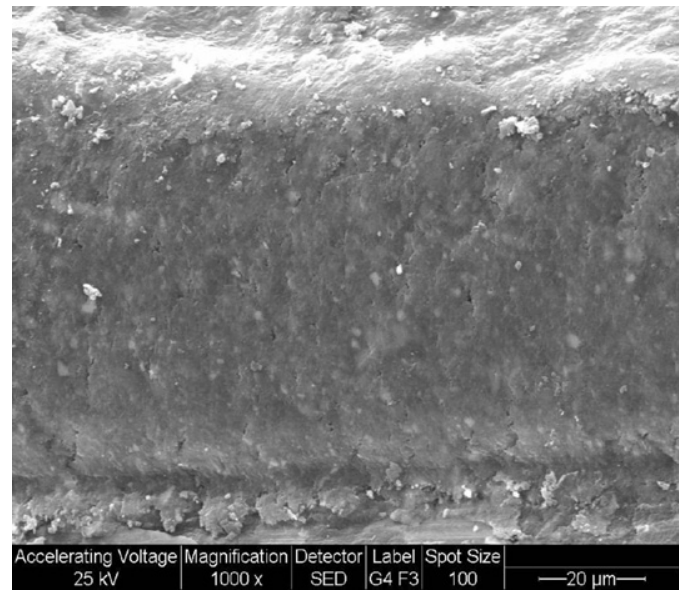

Fig. 6. SEM image of paint $\mathrm{G} 2$ cross section area.

paint W1 (barium sulphate totally replaced by microspheres) performed like paint 5 , with $30 \%(\mathrm{v} / \mathrm{v})$ of zinc phosphate. Paint W2, with 70/30 sphere/barium sulphate ratio had a good protective behaviour until $1100 \mathrm{~h}$, but the panels presented $1 \%$ of the painted surface rusted and few blisters after $1900 \mathrm{~h}$. Paints W3 and 4 were taken out from the cabinet after $1100 \mathrm{~h}$ due the important coating deterioration.

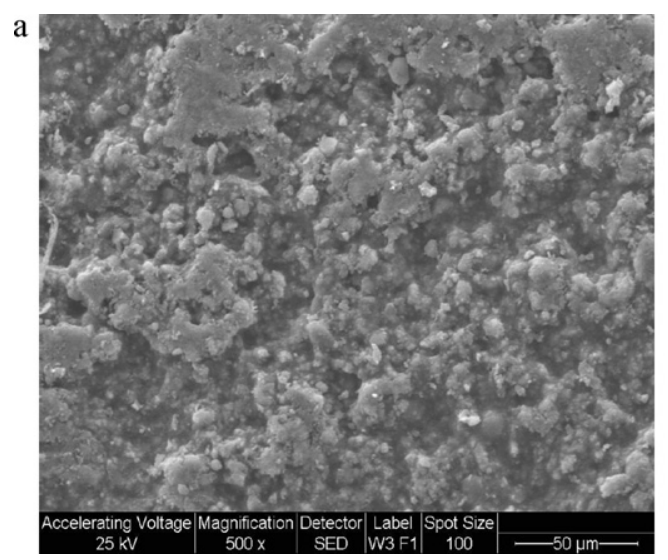

Fig. 8. SEM image of paint W1 (a) surface, (b) cross section.
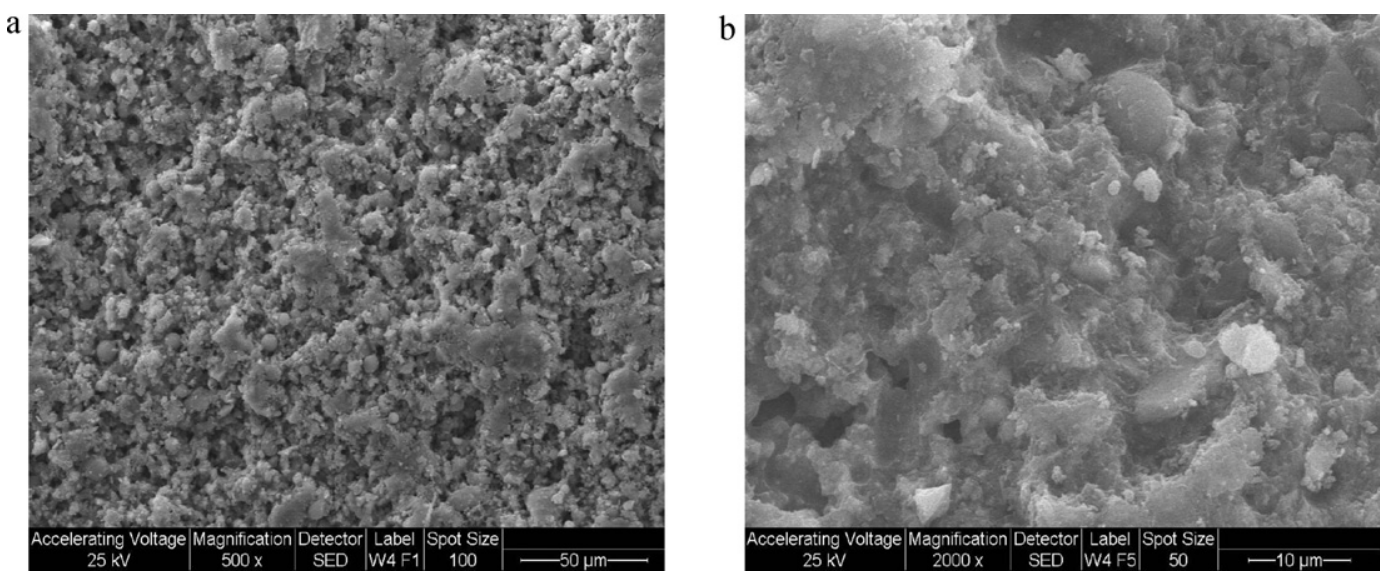

Fig. 9. SEM image of paint W2 (a) surface, (b) cross section.

It must be concluded that as the percentage of microspheres $\mathrm{W}$ increased the anticorrosive properties of the film increased in spite of the lower ZP content. Microsphere G allowed the reduction in the $\mathrm{ZP}$ content independently of their proportion in the pigment mixture.

Paints with microspheres $\mathrm{W}$ and paint 4 failed at the scribe mark after $720 \mathrm{~h}$ in the salt spray cabinet and the failure was

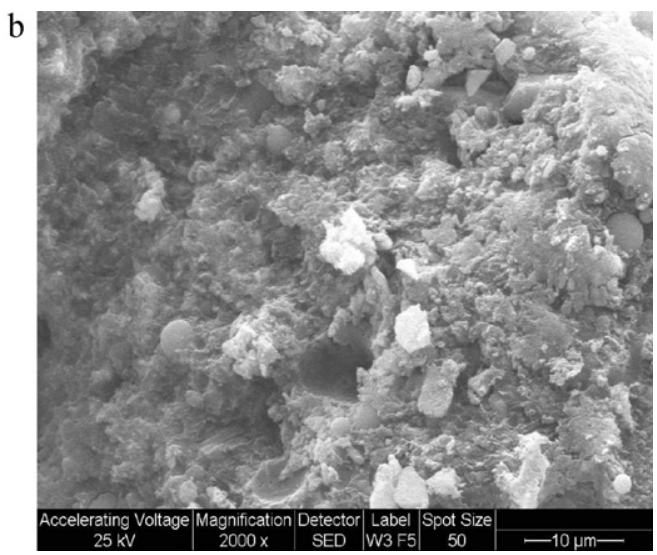



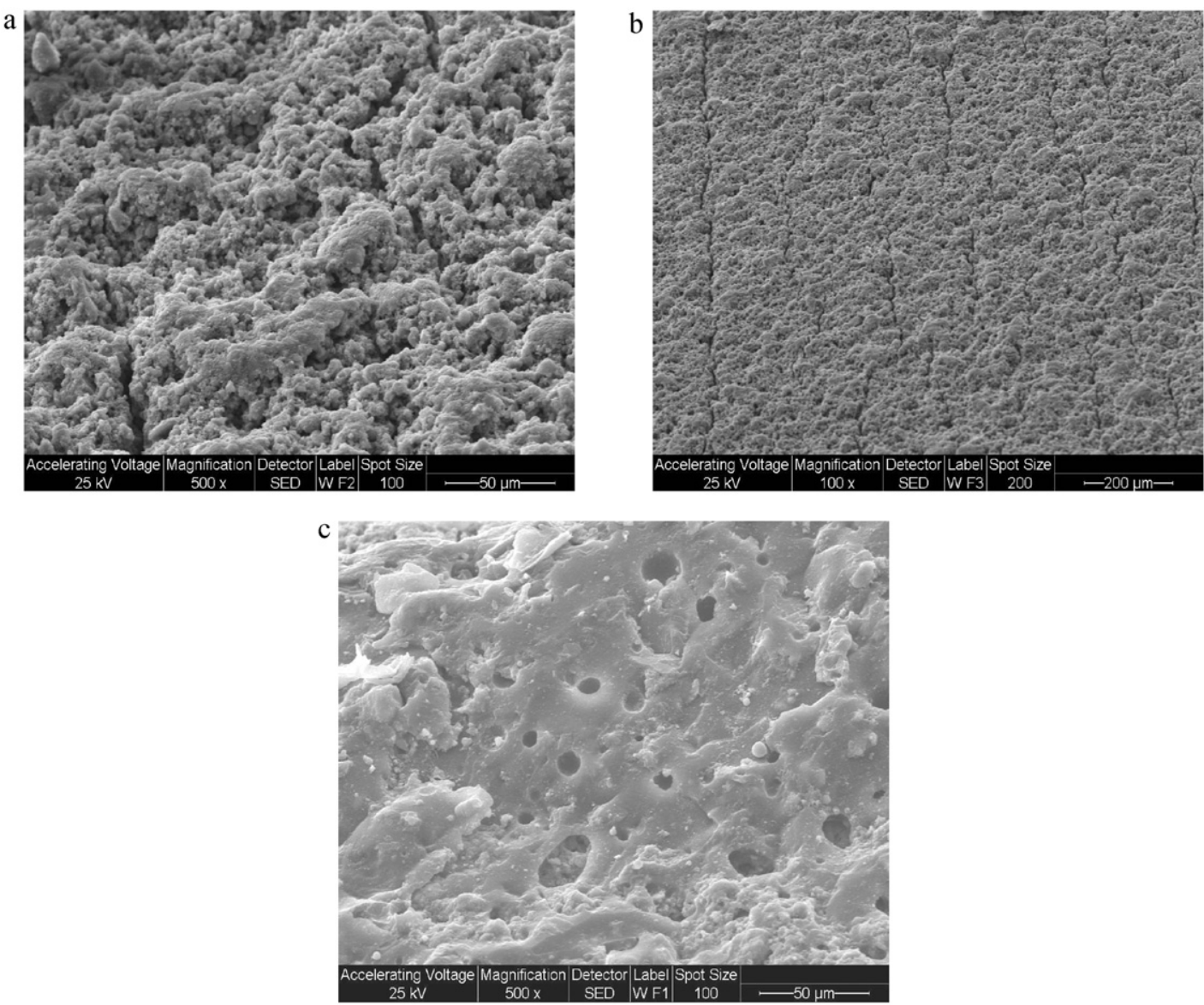

Fig. 10. SEM images of paint W3 (a) and (b) surface, (c) cross section area.

more important as microspheres content decreased. While paint W1 did not protect the exposed metal and corrosion crept $1 \mathrm{~mm}$ from the scratch (qualification 8), paints $\mathrm{W} 2$ and $\mathrm{W} 3$ presented blisters. Panels painted with paint 4 presented blisters and corrosion in the damage areas. Paints with spheres $\mathrm{G}$ protected the exposed metal for more than $1100 \mathrm{~h}$ while paint 5 failed after $1100 \mathrm{~h}$.

Protective properties of paints with spheres $\mathrm{W}$ increased as the microspheres content increased. The anticorrosive behaviour of paints with microspheres $G$ was satisfactory in every case.

In the humidity chamber, all paints blistered in an important way after $200 \mathrm{~h}$ of essay, except paint 4 ; the blistering degree did not change during the test period. After $200 \mathrm{~h}$, only the panel coated with paint 5 had corrosion spots, slight rusting appeared on the surfaces of paint G2 and paints 4 and 5 after $390 \mathrm{~h}$ of testing. The other paints did not exhibit corrosion until $1100 \mathrm{~h}$ of exposure (Table 5).
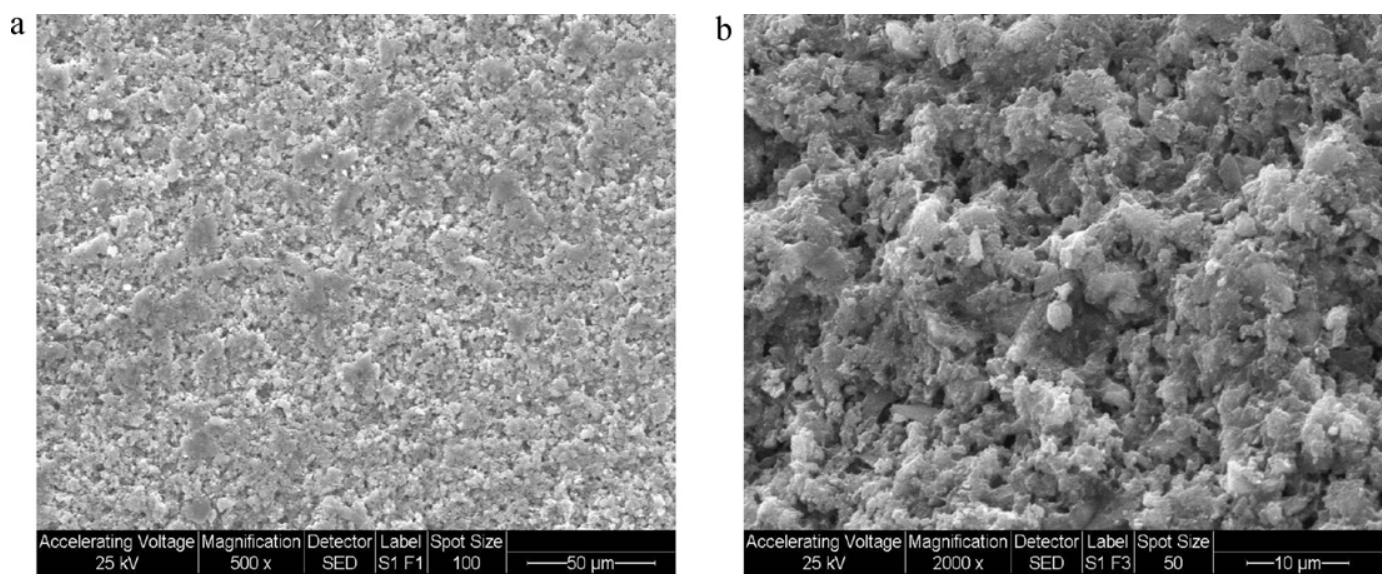

Fig. 11. SEM image of paint 4 (a) surface, (b) cross section area. 


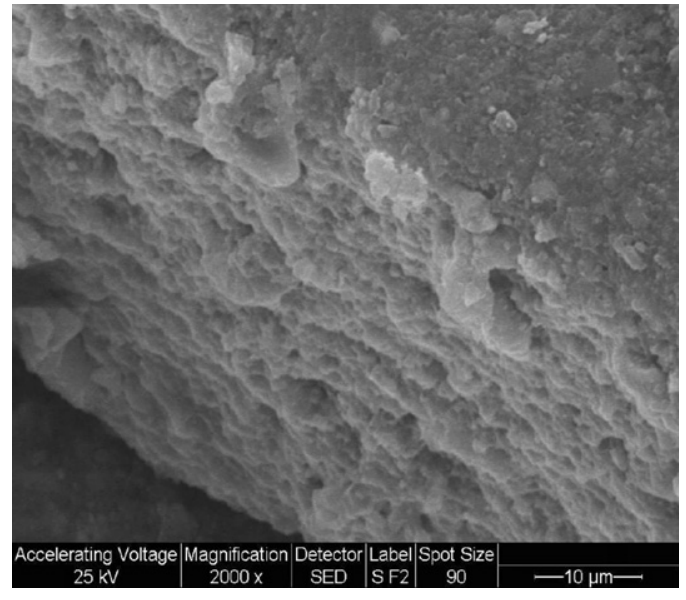

Fig. 12. SEM image of paint 5 natural fracture area.

The barrier protection mechanism of coatings can be assessed by resistance measurements, [30-32]. Szauer [30] proposed a ranking of coatings with full, satisfactory and poor protection defined by the values attained by the ionic resistance (Ri) as

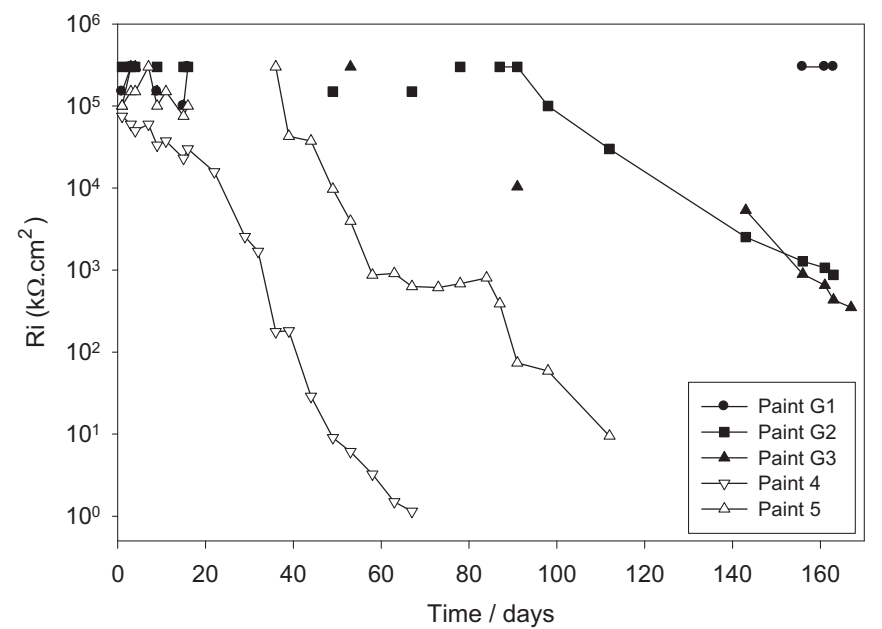

Fig. 13. Ionic resistance of the panels coated with paints pigmented with microspheres and controls.

follows: $\mathrm{Ri}>10^{5} ; 10^{3}<\mathrm{Ri}<10^{5}$ and $\mathrm{Ri}<10^{3} \mathrm{k} \Omega \mathrm{cm}^{2}$, respectively.

Microspheres $\mathrm{G}$ imparted higher ionic resistance to paints than microspheres W. In both types of paints, the barrier effect

Table 4

Rusting (ASTM D 610) and blistering (ASTM D 714) degrees of painted panels after the salt spray test (ASTM B 117).

\begin{tabular}{|c|c|c|c|c|c|c|c|c|}
\hline \multirow[t]{3}{*}{ Paint } & \multicolumn{8}{|c|}{ Hours of exposure } \\
\hline & \multicolumn{3}{|l|}{720} & \multicolumn{3}{|c|}{1100} & \multicolumn{2}{|c|}{1900} \\
\hline & $R^{\mathrm{a}}$ & $B^{\mathrm{b}}$ & $S^{\mathrm{c}}$ & $R^{\mathrm{a}}$ & $B^{\mathrm{b}}$ & $S^{\mathrm{c}}$ & $R^{\mathrm{a}}$ & $B^{\mathrm{b}}$ \\
\hline G1 & 10 & 10 & 10 & 10 & 10 & 10 & 10 & $8 \mathrm{~F}$ \\
\hline G2 & 10 & 10 & 10 & 10 & 10 & 10 & 9 & $2 \mathrm{~F}$ \\
\hline G3 & 10 & 10 & 10 & 10 & 10 & 10 & 9 & 10 \\
\hline W1 & 10 & 10 & 8 & 10 & 10 & 7 & 10 & $6 \mathrm{~F}$ \\
\hline W2 & 10 & 10 & $10^{\mathrm{d}}$ & 10 & 10 & $10^{\mathrm{d}}$ & 6 & $6 \mathrm{~F}$ \\
\hline W3 & 9 & 10 & $10^{\mathrm{d}}$ & 4 & 4 & - & - & - \\
\hline 4 & 9 & $4 \mathrm{~F}$ & $8^{\mathrm{d}}$ & 7 & 7 & - & - & - \\
\hline 5 & 10 & 10 & 10 & 10 & 10 & 7 & 10 & $2 \mathrm{~F}$ \\
\hline
\end{tabular}

${ }^{\text {a }}$ Rusting degree.

\begin{tabular}{|c|c|c|c|c|c|c|c|c|c|c|}
\hline & 10 & 9 & 8 & 7 & 6 & 5 & 4 & 3 & 2 & 1 \\
\hline Rusted area/\% & 0 & 0.03 & 0.1 & 0.3 & 1 & 3 & 10 & 16 & 33 & 50 \\
\hline \multicolumn{11}{|c|}{${ }^{\mathrm{b}}$ Blistering degree. } \\
\hline Frequency & \multicolumn{2}{|c|}{ Dense, D } & \multicolumn{5}{|c|}{ Medium dense, MD } & \multicolumn{2}{|c|}{ Medium, M } & Few, F \\
\hline Size & \multicolumn{2}{|c|}{10} & \multicolumn{5}{|c|}{8} & \multicolumn{2}{|c|}{6,4} & 2 \\
\hline Comments & \multicolumn{2}{|c|}{ No blistering } & \multicolumn{5}{|c|}{ Smaller size blister easily seen by unaided eye } & \multicolumn{3}{|c|}{ Progressively larger sizes } \\
\hline
\end{tabular}

${ }^{\mathrm{c}}$ Failure at scribe.

0

Over $0-0.5$

Over $0.5-1.0$

Over $1.0-2.0$

Over $2.0-3.0$

\footnotetext{
${ }^{\mathrm{d}}$ Blisters were present on the scratch mark.
} 
Table 5

Rusting and blistering degrees of painted panels after the humidity chamber.

\begin{tabular}{|c|c|c|c|c|}
\hline \multirow[t]{3}{*}{ Paint } & \multicolumn{4}{|c|}{ Hours of exposure } \\
\hline & \multicolumn{2}{|l|}{200} & \multicolumn{2}{|l|}{390} \\
\hline & Rusting & Blistering & Rusting & Blistering \\
\hline G1 & 10 & $8 \mathrm{D}$ & 10 & $8 \mathrm{D}$ \\
\hline G2 & 10 & $6 \mathrm{D}$ & 9 & $6 \mathrm{D}$ \\
\hline G3 & 10 & $8 \mathrm{D}$ & 10 & $8 \mathrm{D}$ \\
\hline W1 & 10 & $7 \mathrm{D}$ & 10 & $7 \mathrm{D}$ \\
\hline W2 & 10 & $8 \mathrm{M}$ & 10 & $8 \mathrm{M}$ \\
\hline W3 & 10 & $8 \mathrm{D}$ & 10 & $8 \mathrm{D}$ \\
\hline 4 & 10 & 10 & 9 & 10 \\
\hline 5 & 9 & $8 \mathrm{M}$ & 9 & $8 \mathrm{M}$ \\
\hline
\end{tabular}

was higher for full replacement of barite by the ceramic microspheres (Figs. 13 and 14). Paints formulated with microspheres $G$ underwent strong changes in their ionic resistance which increased beyond the detection limit of the measuring device. In the case of paint G1 these increments were observed for more than 5 months of immersion, the ionic resistance was still high at the end of the test indicating full barrier properties $\left(\mathrm{Ri}>10^{5} \mathrm{k} \Omega \mathrm{cm}^{2}\right)$. The ionic resistance of paints G2 and G3 begun to decrease after 100 days but the barrier properties were satisfactory for 150 days. Control paints, containing no spheres, behaved as it was expected for alkyd paints in the sense that the ionic resistance was high during a more or less brief period at the beginning of the essay and, then, decreased rather quickly. The effect is more pronounced for the paint with the lower zinc phosphate content (paint 4). Ionic resistance of paint 4 , with $10 \%$ of zinc phosphate, diminished continuously during the first month of immersion reaching values lower than $10^{3} \mathrm{k} \Omega \mathrm{cm}^{2}$, thus pointing out that the barrier properties of the paint were lost. The paint with the higher content of zinc phosphate kept its barrier properties for 80 days.

When microspheres $\mathrm{W}$ were employed, only the paint for which $100 \%$ of barite was replaced (Paint W1) behaved like the

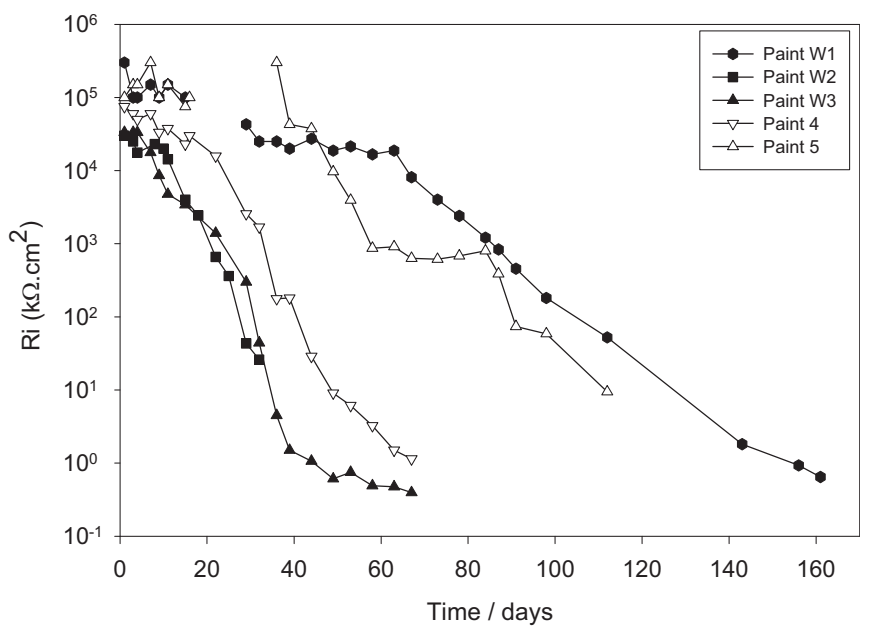

Fig. 14. Ionic resistance of the panels coated with paints pigmented with microspheres and controls.

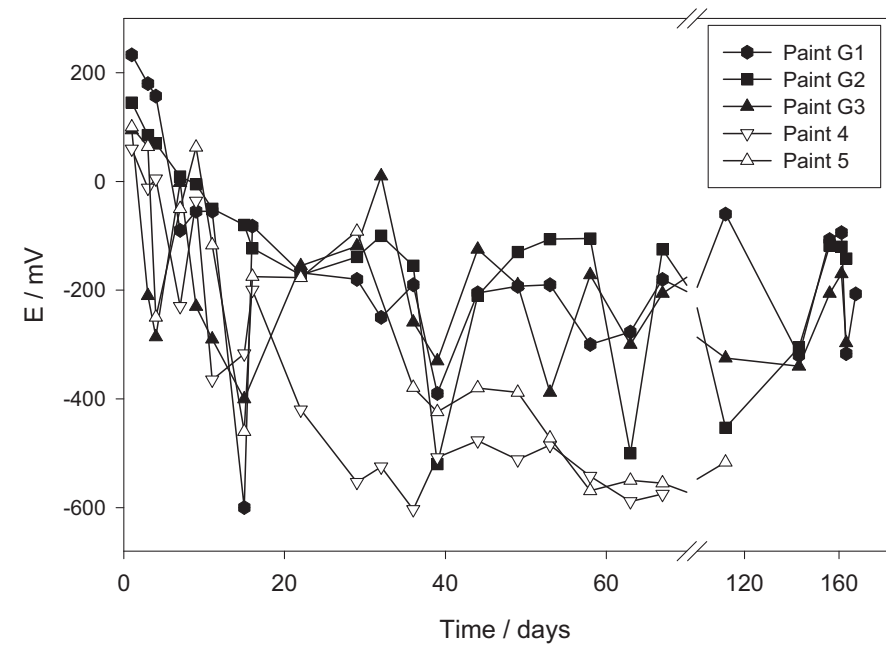

Fig. 15. Corrosion potential of the panels coated with paints pigmented with microspheres and controls.

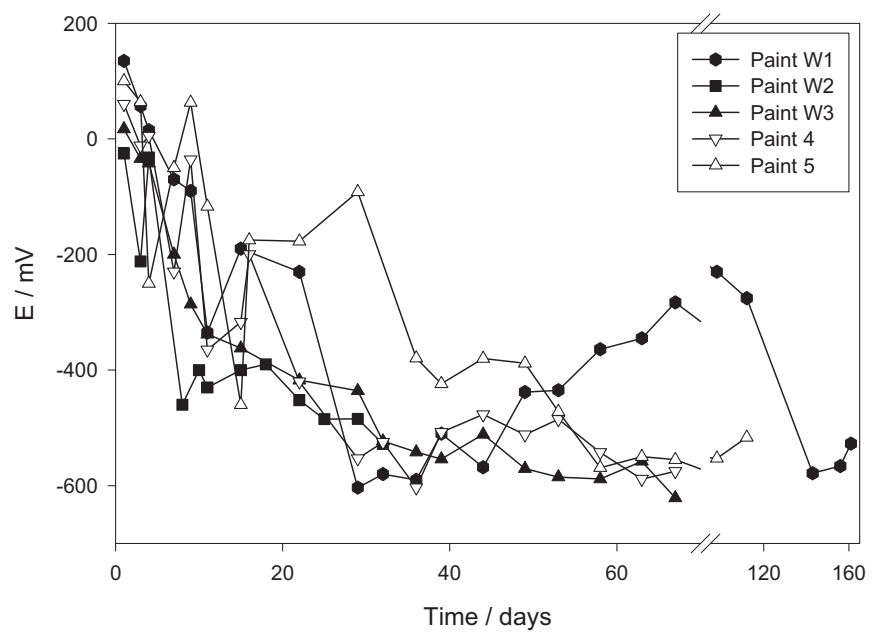

Fig. 16. Corrosion potential of the panels coated with paints pigmented with microspheres and controls.

paint containing 30\% (v/v) of zinc phosphate (Fig. 15). In the rest of the paints no further improvements were obtained by incorporation ceramic microspheres $\mathrm{W}$. The paints with the best behaviour lost their barrier property after 85 days of immersion (Paint W1) while paints G2 and G3 lost their barrier properties after 150 days of immersion.

A painted steel surface could be considered protected if its Ecorr resulted higher than $-0.100 \mathrm{~V}$ [33]. Ecorr of tested panels was more negative than $-0.100 \mathrm{~V}$ for every paint, except at the beginning of the essay (Figs. 15 and 16). Ecorr values oscillated as a consequence of the corrosion-passivation process which was more pronounced and effective in the case of the paints with microspheres G. Ecorr of steel panels coated with paints containing microspheres $\mathrm{G}$ varied, most of the time, between -0.100 and $-0.200 \mathrm{~V}$, thus indicating a good protection degree (Fig. 15). At the end of the test period, Ecorr of paints containing microspheres $G$ was close to $-0.200 \mathrm{~V}$ while Ecorr of paints containing zinc phosphate 
alone descended below $-0.400 \mathrm{~V}$ between 23 and 38 days of immersion. Steel coated with paints containing only zinc phosphate matched Ecorr values of steel undergoing corrosion $(\sim-600 \mathrm{mV})$ after 30 days for paint 4 and after 40 days for paint 5 .

In most cases Ecorr of steel coated with paints containing microspheres $\mathrm{W}$ diminished continuously during the first three weeks of immersion as it occurred with the paint containing $10 \%$ of zinc phosphate. After one month of immersion most panels were corroding as it could be deduced by the Ecorr values. The exceptions were the paint containing $30 \%$ of zinc phosphate and the paint W1 (100\% barite replacement) which showed a certain tendency to repassivation which caused steel to be protected for more than 4 months while the reference paint with the higher zinc phosphate content lost its protective properties after two months of immersion (Fig. 16).

\section{Conclusions}

$\circ$ The ceramic spheres tested in this research do not possess, by themselves, anticorrosive properties

- Spheres G, with lower size and a higher amount of spherical particles, behaved better than spheres $\mathrm{W}$

- Total or partial replacement of barium sulphate by ceramic spheres resulted in noticeable improvement of paints performance due to an increase in the barrier properties of the paints

- As general rule, the employment of ceramic microspheres improved the anticorrosive performance of paints with lower zinc phosphate content.

- Good anticorrosive behaviour was obtained employing spheres $G$ despite the percentage of barium sulphate replacement

- Only when barium sulphate was completely replaced by spheres W paints anticorrosive behaviour was good

- The anticorrosive performance of the paint formulated with the lowest content of microspheres $\mathrm{G}$ and $10 \%$ by volume of zinc phosphate was better than the behaviour of the paint containing the optimum amount of zinc phosphate $(30 \%, \mathrm{v} / \mathrm{v})$

\section{Acknowledgements}

The authors are grateful to CONICET (Consejo Nacional de Investigaciones Científicas y Técnicas), UNLP (Universidad Nacional de La Plata) and CIC (Comisión de Investigaciones Científicas de la Provincia de Buenos Aires) for their sponsorship to do this research. The authors also thanks to Raúl Pérez for the analytical determinations, POLIDUR S. A. for providing the alkyd resin and to Daniel Erasmo from $3 \mathrm{M}$ for providing the ceramic spheres.

\section{References}

[1] F. de, L. Fragata, J.E. Dopico, Anticorrosive behavior of zinc phosphate in alkyd and epoxy binders, JOCCA 3 (1991) 92-97.

[2] J.A. Burkill, J.E.O. Mayne, The limitations of zinc phosphate as an inhibitive pigment, JOCCA 9 (1988) 273-285.
[3] J. Harrison, The function of zinc phosphate in protective coatings, Trans. Inst. Metal Finish. 48 (1970) 83-87.

[4] R. Romagnoli, V. Vetere, Non pollutant corrosion inhibitive pigments: zinc phosphate, a review, Corros. Rev. XIII (1) (1995) 45-64.

[5] E.P. Odum, 3rd ed., Ecología, 1972, pp. 117-118.

[6] Phosphate removal: a novel approach. J.W. Mc Grath, J.P. Quinn, Queen's University, Belfast, www.qub.ac.uk/envres/EarthAirwater/ phosphate-removal.htm.

[7] A. Gerhard, A. Bittner, Second generation phosphate anti-corrosive pigments. Formulating rules for full replacement of new anti-corrosive pigments, JCT 58 (1986) 59-63.

[8] A. Bittner, Advanced phosphate anticorrosive pigments for compliant primers, JCT 61 (1984) 114-118.

[9] A. Bittner, J. Ruf, Testing of phosphates in anticorrosive primers, PPCJ (October) (1997) 22-25.

[10] M. Bethencourt, F. Botana, M. Marcos, R. Osuna, J. Sánchez-Amaya, Inhibitor properties of green pigments for paints, Prog. Org. Coat. 46 (2003) 280-287.

[11] R. Romagnoli, C. Deyá, B. del Amo, The mechanism of the anticorrosive action of calcium-exchanged silica, JCT 86 (B2) (2003) 135-141.

[12] L.W. Vasconcelos, I.C.P. Margarit, O.R. Mattos, F.L. Fragata, A.S.B. Sombra, Inhibitory properties of calcium exchanged silica epoxy paintings, Corros. Sci. 43 (2001) 2291-2303.

[13] B.P.F. Goldie, Calcium exchanged silica anticorrosion pigment: a review, JOCCA 9 (1988) 257-269.

[14] B. Chico, J. Simancas, J.M. Vega, N. Granizo, I. Díaz, D. de la Fuente, M. Morcillo, Anticorrosive behavior of alkyd paints formulated with ionexchange pigments, Prog. Org. Coat. 61 (2008) 283-290.

[15] A. Kalendová, Anticorrosive spinel-type pigments of the second generation, Pig. Res. Technol. 27 (4) (1998) 225-230.

[16] A. Kalendová, Alkalizing and neutralizing effects of anticorrosive pigments containing Zn, Mg, Ca and Sr cations, Prog. Org. Coat. 38 (2000) 199-206.

[17] P. Mošner, A. Kalendová, L. Koudelka, Anticorrosion properties of SrO$\mathrm{ZnO}-\mathrm{B}_{2} \mathrm{O}_{3}-\mathrm{P}_{2} \mathrm{O}_{5}$ pigments, Dyes Pig 45 (2000) 29-34.

[18] P. Kalenda, A. Kalendová, V. Stengl, P. Antos, J. Subrt, Z. Kvaca, S. Bakardjieva, Properties of surface-treated mica in anticorrosive coatings, Prog. Org. Coat. 49 (2004) 137-145.

[19] W. Funke, Towards environmentally acceptable corrosion protection by organic coatings, JCT 55 (1983) 31-38.

[20] B. Bieganska, M. Zubielewicz, E. Smieszek, Influence of barrier pigments on the performance of protective organic coatings, Prog. Org. Coat. 16 (1988) 219-229.

[21] J.-M. Yeh, K.-C. Chang, Polymer/layered silicate nanocomposite anticorrosive coatings, J Ind Eng Chem 14 (2008) 275-291.

[22] J.-M. Yeh, C.-L. Chen, Y.-C. Chen, C.Y. Ma, K.-R. Lee, Y. Wei, S. Li, Enhancement of corrosion protection effect of poly(o-ethoxyaniline) via the formation of poly(o-ethoxyaniline)-clay nanocomposite materials, Polymer 43 (2002) 2729-2736.

[23] K.-C. Chang, M.-C. Lai, C.-W. Peng, Y.-T. Chen, J.-M. Yeh, C.-L. Lin, J.-C. Yang, Comparative studies on the corrosion protection effect of DBSA-doped polyaniline prepared from in situ emulsion polymerization in the presence of hydrophilic $\mathrm{Na}^{+}$-MMT and organophilic organo-MMT clay platelets, Electrochim. Acta 51 (2006) 56455653.

[24] S. Sathiyanarayanan, S. Syed Azim, G. Venkatachari, Corrosion protection coating containing polyaniline glass flake composite for steel, Electrochim. Acta 53 (2008) 2087-2094.

[25] J. Santos, L. Mattoso, A. Motheo, Investigation of corrosion protection of steel by polyaniline films, Electrochim. Acta 43 (1998) 309-313.

[26] M.C. Deyá, G. Blustein, R. Romagnoli, B. del Amo, Zinc hypophosphite: a suitable additive for anticorrosive paints to promote pigments synergism, JCT Res 6 (3) (2009) 369-376.

[27] A. Kalendová, D. Veselý, J. Stejskal, Organic coatings containing polyaniline and inorganic pigments as corrosion inhibitors, Prog. Org. Coat. 62 (2008) 105-116.

[28] Technical sheet of microspheres G: $3 \mathrm{M}$ Zeeospheres ${ }^{\mathrm{TM}}$ Ceramic Microspheres Gray Grades. 
[29] Technical sheet of microspheres W: $3 \mathrm{M}$ Zeeospheres ${ }^{\mathrm{TM}}$ Ceramic Microspheres White Grades.

[30] T. Szauer, Electrical and electrochemical resistances for the evaluation of protective non-metallic coatings, Prog. Org. Coat. 10 (1982) 157-170.

[31] H. Leidheiser jr., Electrical and electrochemical measurements as predictors of corrosion at the metal-organic coating interface, Prog. Org. Coat. 7 (1979) 79-104.
[32] D. Mills, K. Schaefer, Use of electrochemical methods to examine different surface preparation methods for organic coatings on steel, Prog. Org. Coat. 69 (2010) 193-198.

[33] C.I. Elsner, A.R. Di Sarli, Comparison between electrochemical impedance and salt spray test in evaluating the effect of epoxy paints, J. Braz. Chem. Soc. 5 (1) (1994) 15-18. 